If certain measures (care of the cervical spine, intubation and ventilation, setting up an intravenous line, splinting fractured limbs) are performed at the scene of the accident and the critically injured patient is transferred to the appropriate hospital by the appropriate means within the "golden hour" morbidity and mortality can be reduced. Other interventions (such as fluid resuscitation and applying military antishock trousers) that entail a philosophy of "stabilise then mobilise" are less beneficial than those entailing a philosophy of "scoop and run," especially in urban areas. This may not be true, however, if the transfer to hospital takes longer than 20 minutes.

The Royal College of Surgeons of Edinburgh holds courses for the diploma in immediate care, and there are British textbooks and other courses specifically on this subject. The Royal Army Medical Corps runs a battlefield army trauma life support course based on the principles of advanced trauma life support. It caters for the field management of casualties without the sophistication of hospital care and thus meets the criteria of the immediate care module suggested by Mowat.

It is not only, however, the immediate care of patients with trauma that needs to be addressed but also the continuum of care (from the scene of the accident to rehabilitation) and accident prevention. Successful care is care that returns an injured patient to society quickly.

North Western Injury Research Centre,

W F DE MELLO

Manchester M13 9PT

Cambridge Military Hospital,

J RESTALL

Aldershot GU11 2AN

1 Mowat AJ. Advanced trauma life support courses. BMJ 1992 304:1114-5. (25 April.)

2 Trunkey DD. Prehospital care. In: Trunkey DD, Lewis FR, eds. Current therapy in trauma. Philadelphia: B C Decker, 1991:3.

\section{Behçet's disease}

SIR, - B Wechsler and J C Piette have mysteriously omitted to mention chlorambucil as a treatment in Behçet's disease.' This alkylating agent may have a useful role in preventing recurrent episodes of uveitis and encephalopathy in the disease. ${ }^{23}$

Recurrent ocular symptoms may progress to loss of useful vision within 10 years in a considerable proportion of people. ${ }^{+}$Death and permanent deficit after Behçet's disease affecting the centra nervous system have been well documented.56 As corticosteroids may not ultimately preven blindness or death, ${ }^{7}$ chlorambucil should be considered in appropriate patients despite its small risk of oncogenicity.

G P R CLUNIE

Department of Rheumatology,

Whittington Hospital,

London N19 5NF

1 Wechsler B, Piette JC. Behçet's disease. BMJ 1992;304 1199-200. (9 May.)

2 Mamo JG, Azzam SA. Treatment of Behçet's disease with chlorambucil. Arch Ophthalmol 1970;84:446-50.

O'Duffy JD, Robertson DM, Goldstein NP. Chlorambucil in the treatment of uveitis and meningoencephalitis of Behçet's disease. Am $\mathcal{F}$ Med 1984;76:75-84

4 Benezra D, Cohen F. Treatment and visual prognosis in Behçet's disease. Br 7 Ophthalmol 1986;70:589-92.

5 Wolf SM, Schotland DL, Phillips LL. Involvement of nervous olf SM, Schotland DL, Phillips LL. Involvement of nerv
system in Behçet's syndrome. Arch Neurol 1965;12:315-25.

6 Chajck T, Fainaru M. Behçet's disease; report of 41 cases and review of the literature. Medicine 1975;54:179-96.
rever

7 O'Duffy JD. Behçet's syndrome. N Engl f Med 1990;322:326-7.

\section{Diagnosing pulmonary embolism}

SIR,-We welcome N W Morrell and W A Seed's pragmatic approach to the difficult problem of reliably diagnosing pulmonary emboli. Ventilation-perfusion scans are often requested and relied on to confirm or exclude pulmonary embolus. Misgivings about the reliability of the test led us to audit the scans obtained in ou hospital and assess the consistency of reporting among radiologists.

During 1991, 608 lung scans were obtained, of which we located 567. Altogether 162 (29\%) were reported as being "high probability" scans and 330 $(58 \%)$ as "low probability" scans, which is a much lower proportion than that in the studies quoted by Morrell and Seed. ${ }^{23}$ In our study only $15 \%$ of the patients would have required a further procedure to determine whether they had pulmonary emboli by Morrell and Seed's criteria.

When five consultant radiologists who regularly report isotope lung scans were presented with 10 scans, clinical information, and chest $x$ ray films - simulating the normal reporting conditions -inconsistent results were produced. In each case the majority opinion was assumed to be correct. On this assumption, the original scan had been misreported in four of the 10 cases in a way that would have altered the diagnosis and subsequent management. The original report had been of low probability in three cases; one scan initially reported as high probability was reported by the consultants as low probability. If these results are representative, up to $40 \%$ of reports may be misleading.

A practical strategy for dealing with scans that fall between low and high probability scans is useful, but we need to be sure that the initial categorisation is correct more than $60 \%$ of the time.

K A MCLEAN TASNEEM RANA DAVID POLLARD K S CHANNER

Cardiology Department, Royal Hallamshire Hospital, Sheffield S10 2JF

1 Morrell NW, Seed WA. Diagnosing pulmonary embolism. $B M$ 1992;304:1126-7. (2 May.)

2 Hull RD, Hirsh J, Carter CJ, Raskob GE, Gill GJ, Jay RM, et a a

Diagnostic value of ventilation-perfusion lung scanning in patients with suspected pulmonary embolism. Chest in patients with

3 PIOPED Investigators. Value of the ventilation/perfusion scan in acute pulmonary embolism. FAMA 1990;263:2753-9.

\section{Free For All: "Cancer positive"}

SIR,-Jeffrey Tobias is entitled to his opinion of our programme, but he should not mislead readers over facts.

Firstly, he seems to suggest, incorrectly, that patients treated at the Bristol centre who were included in the study reported in the Lancet were not having orthodox treatment.

Secondly, he says that these patients "still seemed to do worse in the long run." This was never stated, even by the researchers: Bristo patients were observed for an average of only six months.

Thirdly, with regard to overall survival, the press release put out by the Imperial Cancer Research Fund and the Cancer Research Campaign in September 1990 quite properly stated, "it is still too soon to compare overall survival!" Even if the study was continuing this would still be true: some patients were entered into the study less than five years ago.

Fourthly, the woman who said that some doctors would "throw you out of the room" at the mention of the Bristol centre also said of other doctors: "They'll be, oh, great, especially the younger ones.

They're very keen and ask you all about it." Tobias seems anxious to polarise the discussion. We would like the two sides to come together, and we believe that orthodox and complementary medicine can and should gel, as they already do in many NHS hospitals.

Fifthly, it was not Penny Brohn who said that "the charities' publicity machine made sure it was made public" but ourselves, in our commentary.
The Bristol Cancer Help Centre had no hand in making the programme.

Sixthly, the report did not analyse the effect of treatments on offer at Bristol; indeed, the researchers made no use of the questionnaires which would have documented compliance.

Finally, the "sensational story" was not "gobbled up" by the tabloid papers any more than by the quality press. The $B M \mathcal{F}$ gave it 39 column inches in September 1990, the Times 20, and the Sun only three.

It seems to need restating that, in the words of Sir Walter Bodmer himself, "women going to Bristol had more severe disease than control women." $\mathrm{He}$ was good enough to apologise on camera for the distress caused, saying: "I am very sorry that a mistake was made." A further important point is that the Bristol women were younger than the controls, and evidence shows that breast tumours tend to grow faster in younger women.

What scientific conclusions, if any, may be drawn from such a study is, in our view, a matter for an independent inquiry. We agree that a review committee should have pointed out major flaws. The problem was that no review committee did so.

ISLA BOURKE

HEATHER GOODARE

Horsham

West Sussex RH13 6DF

1 Tobias J. Publish and be damned BMf 1992:304:991. (11 April.)

2 Cheung CWD, Johnson AE. Carcinoma of the breast: measurement and the management of treatment. Br $\mathcal{F}$ Radiol 1991;64: $121-32$.

\section{Improving postgraduate training in ophthalmology}

SIR,-J H Sheldrick and colleagues sought to obtain information on undergraduate and postgraduate ophthalmic training by analysing diagnostic accord between general practitioners and an ophthalmologist.' Their finding of agreement in nearly $60 \%$ of cases suggests that training in ophthalmology must be reasonably good. Though they acknowledge that this was a self selected group of general practitioners working under abnormal conditions, I think that they have seriously underestimated the effect that this has on any conclusions that may be drawn from their study.

The quality and nature of referrals from primary care to ophthalmic casualty and outpatient departments are valid reflections of the adequacy of training. The aims of training should be to instruct in the management of simple eye conditions (such as blepharitis) and to provide awareness of more serious problems (usually visual) requiring referral. In a recent audit of 102 referrals to the clinic at $\mathrm{St}$ Paul's Eye Hospital I found that in $34 \%$ of cases the urgency of the outpatient appointment could not be assessed because inadequate information had been provided. In only $55 \%$ were symptoms described, and in only $23 \%$ was the duration of symptoms mentioned. It is more important for a referral letter to include the history and results of simple examination (including visual acuity) than for it to include a suggested diagnosis.

Standard referral forms have been advocated. Issuing general practitioners with such forms, with examples, could be an important step in postgraduate training. Improving the quality and promptness of the hospital's reply to the general practitioner is another potential opportunity for education. Bringing the ophthalmologist into the general practitioner's surgery, as proposed by some fundholders, ${ }^{3}$ may be the ideal solution but is probably feasible on only a small scale.

CLAIRE E MORTON

St Paul's Eye Hospital,

Liverpool L3 9PF 